\title{
O HORIZONTE FEMININO, A PAISAGEM DA TERRA E O LIRISMO DA BUGANVÍLIA: IMAGENS (PO)ÉTICAS EM COMO VEIAS FINAS NA TERRA, DE PAULA TAVARES
}

THE FEMALE HORIZON, THE LANDSCAPE OF THE EARTH AND THE LYRICISM OF BUGANVILIA: (PO)ETHIC IMAGES IN COMO AS VEIAS FINAS NA TERRA, BY PAULA TAVARES

EL HORIZONTE FEMENINO, EL PAISAJE DE LA TIERRA Y EL LIRISMO DE LAS BUGANVILLAS: IMÁGENES (PO)ÉTICAS EN COMO VEIAS FINAS NA TERRA, DE PAULA TAVARES

\section{RESUMO}

Este artigo tem por objetivo estudar a representação do horizonte feminino, da paisagem da terra e o que pode ser chamado de "lirismo da buganvília" no último livro (então publicado), Como veias finas na terra, da poeta angolana Paula Tavares. Para tanto, utilizar-se-á a metodologia teórica de Michel Collot.

PALAVRAS-CHAVE: poesia angolana, Ana Paula Tavares, paisagem.

\section{ABSTRACT}

This article intends to study the representation of the female horizon, the earth landscape and what can be called "bougainvillea lyricism" in the last book (published to date), Como veias finas na terra, by the Angolan poet Paula Tavares. For this purpose, Michel Collot will be used theoretically.

1 Doutorando da UFRJ, Mestre em Literatura Portuguesa pela Universidade do Estado do Rio de Janeiro. Foi membro da equipe brasileira "Novas Cartas Portuguesas: 40 anos depois", sob a coordenação do professor doutor Jorge Fernandes da Silveira. Atuou, de 2012 a 2014, como professor substituto de Literatura Portuguesa na Faculdade de Letras da Universidade Federal do Rio de Janeiro. 
KEYWORDS: Angolan poetry, Ana Paula Tavares, landscape.

\section{RESUMEN}

Este artículo pretende estudiar la representación del horizonte femenino, el paisaje de la tierra y lo que se puede llamar de "lirismo de buganvilla" en el último libro (hasta entonces publicado), Como veias finas na Terra, de la poeta angoleña Paula Tavares. Se utilizará la metodología teórica de Michel Collot.

PALABRAS-CLAVE: Poesía angoleña, Paula Tavares, paisaje.

\section{Introdução}

Segura para mim o tempo

Dizias

Enquanto movias a mão

Como folha se vira para a luz

A sombra desenha-se na parede

Avanças

Ah tanta estrada

Nessa mão parada

(TAVARES, 2011, p.225)

Paula Tavares é uma poeta angolana contemporânea, cuja produção literária está inserida, segundo a crítica especializada, na geração dos anos de 1980 - pós-revolução dos Cravos e pós-independência de Angola. A obra da autora apresenta uma escrita marcada pela desilusão oriunda da guerra civil e da própria condição periférica de seu país. Entretanto, vale comentar, não está alienada politicamente. Afinal, o político em sua escrita se revela em uma dimensão micro (através do afeto, do sexo e do corpo), como será apresentado ao longo da análise.

Este trabalho tem como objeto de estudo o último livro da poeta, Como veias finas na terra. Para tanto, buscar-se-á, através da leitura dos poemas, pensar em como a autora, partindo do horizonte ${ }^{2}$ - que gira em torno do feminino -, articula uma poesia, cujo elemento terra se transforma numa paisagem especial, porque eminentemente literária. Pretende-se refletir sobre

2 O termo é usado no sentido de uma paisagem literária, conforme propôs Michel Collot (2010). 
o lirismo da "buganvília", isto é, uma espécie de linguagem poética/ética de resistência, entre o passado e o presente, em tensão, e que engloba a imagem da terra e da mulher.

Para tanto, este artigo está dividido em duas partes principais: a) A língua do sul: ensaísmo e "literatura menor" - considerações sobre a poesia de Paula Tavares, em que se discutirá a importância do gênero ensaio na leitura da poesia de Paula e se tecerão algumas considerações sobre sua produção literária; b) "O horizonte feminino, a paisagem da terra e o lirismo da buganvília, em Como as veias finas na terra”, onde se analisarão mais detalhadamente os poemas da autora.

A língua do sul: ensaísmo e "literatura menor"3 - considerações sobre a poesia de Paula Tavares

$$
\begin{aligned}
& \text { Cruza sobre mim } \\
& \text { As pontas do vento } \\
& \text { E orienta-as a sul } \\
& \text { Pelo sol }
\end{aligned}
$$$$
\text { (TAVARES, 2011, p.187) }
$$

Diferentemente da ciência (stricto sensu) que subjuga os outros estudos na sua relação hierárquica de "poder-saber-verdade", a crítica - mais propriamente o ensaio sobre a literatura -, busca sempre uma justa proximidade ${ }^{4}$ escritural com o seu objeto epistemológico; logo, assume, assim, uma característica híbrida, como apontou Luiz Costa Lima (1993), ao designá-la "discurso intervalar", que não é uma linguagem artística, mas, muitas vezes, se torna híbrida, ao dialogar com os discursos das artes.

Foi pensando sobre isso que Eduardo Prado Coelho (s/d) utilizou o conceito de "mimésis consistente da incompletude" (COELHO, s/d., p.17), a saber, um discurso que visa a se aproximar de um "modo literário" (Idem), e, ao mesmo tempo, "manter uma pretensão teórica", sem criar "simulacros de apropriabilidade" (Idem), como faziam as correntes de leituras que marcaram os anos sessenta: o Estruturalismo e o Formalismo Russo. Sobre essa questão é importante assinalar que nenhum sistema formal consegue captar, por mais rico que ele seja, a complexidade e a variedade do mundo. Tal pretensão sempre se mostrará frágil e aquém.

Logo, a literatura, ao se colocar como um discurso de "inapropriabilidade" e de fluidez, nunca terá o seu "metanível” (Idem, p. 17) violado. Contudo, se não encaramos esse "metanível" como um espaço em que se situa um observador com um ponto de vista totalizante em relação

3 O título deste capítulo faz referências ao ensaio "A Língua da água", de Eduardo Prado Coelho, presente no livro A mecânica dos fluidos (s/d), e também ao livro Kafka, para uma literatura menor, de Gilles Deleuze e Félix Guattari (2003).

4 Tal proximidade se dá por "semelhança", não por "essência", ou seja, à maneira dos retratos que buscam representar uma pessoa, realizando uma representação. (LUKÁCS, 2008, p. 5). 
à leitura da obra, mas, sim, como "um plano de corte arbitrário" (Idem, p. 18) e importante para o avanço da leitura, conseguiremos que o crítico e o seu objeto de análise se justifiquem numa invenção mútua. Com isso, define-se aquilo que é chamado de "língua" (Idem), à maneira do ensaio de Coelho, no qual ancoramos nossa abordagem de leitura da poética de Paula Tavares.

Entretanto, o que seria essa "língua do sul”? Segundo Boaventura de Sousa Santos:

O sul é aqui concebido como um campo de desafios epistémicos, que procuram reparar danos e impactos historicamente causados pelo capitalismo na sua relação colonial com o mundo. Esta concepção sobre o sul pressupõe-se em parte com o sul geográfico, o conjunto de países e regiões do mundo que foram submetidos ao colonialismo europeu (...) (SANTOS, 2009, p.12)

O sul, portanto, representa uma forma de denunciar a supressão em relação aos conhecimentos produzidos nessas zonas abaixo do Equador, os quais valorizam os saberes que resistiram ao colonialismo e promovem diálogos contemporâneos. Nesse sentido, gostaríamos de pensar o sul como uma metáfora geográfica e ideológica da poesia de Paula Tavares que sempre resistiu e caminhou nessa direção:

Todos nós somos de um lugar, de uma infância, disse o poeta. Nasci na Huíla, no meio de uma sociedade colonial injusta. Os pastores estavam ali. À sociedade Nyaneka eu devo a poesia, a música, o sentido do cheiro, a orientação a sul. (TAVARES, 2010)

A poesia de Paula Tavares é uma “episteme”. Logo, uma forma de conhecimento específica: literária - que se orienta para o sul, geograficamente e ideologicamente -, filha do pós-colonialismo, portadora de uma atitude a contrapelo perante os discursos ocidentais, coloniais, "nortistas" e globalizados que esterilizaram o sul, enquanto espaço de experiências e conhecimento. Por isso, ser uma "literatura do sul" é se aproximar daquilo que Gilles Deleuze e Félix Guattari (2003) chamaram de "literatura menor". Ou seja, não é uma literatura de valor diminuído, mas uma literatura que traça linhas de fuga e possibilita a invenção de novas forças. A partir disso, é possível encontrar os sinais que caracterizam a resistência política e a busca da identidade na poética de Paula Tavares: “À força da voz e no meio da língua fundamos o nosso lugar no mundo e levantamos a utopia quando a terra gela a frio intenso" (TAVARES, 1998, p. 14).

Escrever a "língua do sul", enquanto texto ensaístico sobre a poesia da angolana Paula Tavares, é, desse modo, não fugir de nosso objeto de estudo, "não sobrepor ao texto as muletas da teoria com o risco de trabalhar longe do aprendizado que se faz a cada texto e impor rigores de uma leitura construída para lá do que está escrito” (TAVARES Apud SECCO, 2014, p.102).

\section{Do horizonte feminino, da paisagem da terra e do lirismo da buganvília em Como as veias finas na terra}


Os poemas de Como as veias finas da terra (2010) e dos livros anteriores de Paula são como os rios que penetram a nação angolana, como sangue que oxigena o corpo da terra, como poesia que ativa a circulação da vida, tomada essa em seu sentido natural, cultural espiritual, em suma, em seu sentido pleno. (SECCO, 2011, p.262)

\title{
O horizonte
}

Conforme foi exposto anteriormente, a poesia de Paula Tavares é uma poesia do sul - geograficamente e ideologicamente -, na medida em que promove linhas de fuga pela linguagem através da reinvenção da oralidade e assume marcas de resistência. Por esta via, tais marcas se traduzem num "horizonte" centrifugador, que aborda criticamente o feminino, questão presente desde seus primeiros livros até Como as veias finas na terra, objeto de análise deste ensaio:

(...) Paula foi uma das responsáveis para fundação, em Angola, de uma nova diç̧ão poética que repensava a questão da sexualidade reprimida das mulheres e não se eximia de refletir sobre as desilusões sociais, mostrando-se contrária à opressão e à dor. (SECCO, 2011, p. 262)

Ao nos referirmos ao "horizonte", não podemos deixar de recorrer aos atuais estudos sobre paisagem de Michel Collot, principalmente ao ensaio "Do Horizonte da Paisagem ao Horizonte dos Poetas" (2010), em que define o "horizonte" literariamente como aquilo que, na paisagem, limita e torna ilimitado, "abrindo uma profundidade, na articulação do visível e do invisível - esta distância que é o palmo de nossa presença no mundo, este batimento do próximo e do longínquo que é a própria pulsação da nossa existência” (COLLOT, 2010, p. 205).

Nesta articulação do 'visível e do invisível', da "luz e [da] sombra" - parafraseando o título do poema que abre o livro estudado -, o eu-lírico enuncia e anuncia, através dos seus "novos cadernos de Fabro", a característica do entre-lugar: "De tinta não há notícias mas sinais/ velhos sinais perdidos nas dunas e na areia” (TAVARES, 2011, p. 217). Afinal, o "visível” está para a "luz" e para as "notícias"; o "invisível", para a "sombra" e, por conseguinte, para os "velhos sinais perdidos nas dunas e nas areias", mas presentes nas "veias finas na terra". Sinais soterrados, que se encontram num museu da Alemanha, na imagem dividida e roubada do busto de Nefertiti:

\author{
Esta cabeça é minha \\ por cima do muro \\ que a sustém \\ Esta cabeça está cortada de mim \\ há sete mil anos \\ e no entanto é a voz dela
}


que fala dentro da minha voz

o seu olho vazado que me ilumina

os olhos

(TAVARES, 2011, p. 228)

Busto que convoca o sujeito-lírico, no reconhecimento em relação ao outro, a se colocar para fora de si, como propõe Collot, em "O Sujeito Lírico Fora de Si”. E, também, a se posicionar entre o "próximo" e o "longínquo". Por esta via, o eu-lírico cria um processo de identificação com sua própria terra. Vale lembrar que a poeta traz para sua poesia mulheres da etnia Mumuíla, expressando poeticamente o universo local dos povos pastores do sudoeste angolano.

Todavia, o fato de o sujeito lírico se referir “à cabeça de Nefertiti” nos leva a perceber que a poeta de Amargos como os frutos alarga o horizonte do feminino local - as mulheres do sul de Angola - e busca uma sororidade africana mais ampla temporalmente.

\author{
Estico até a seda \\ o fio das palavras \\ as palavras são como os olhos das mulheres \\ fios de pérolas ligados pelos nós da vida.
}

(TAVARES, 2011, p.244)

De acordo com Carmen Secco,

A poesia de Paula nos entra pelas veias, nos apanha por inteiro, levando-nos a reflexões, em meio a sensações intensas. Cada verso seu estica, ao máximo as palavras, tirando, de cada uma, múltiplos sentidos. É arco e lira, é seda e lã. É areia e água, terra e cheiros, frutos e desertos. (SECCO, 2011, p. 279)

Conforme o poema, as palavras são como a vida das mulheres, interligadas, mesmo geograficamente dispersas. Na poesia de Paula,

diluem-se os mitos vazios de um feminismo retórico ou de um tradicionalismo exotizante para dar lugar à visão de um grupo que intervém na sociedade em que está inserido. Dessa maneira, Ana Paula não fala pelas mulheres de sua terra ou de outras, fala com elas, abre-lhes o lugar que elas já ocupam. É essa uma das maneiras de denunciar uma das muitas injustiças dos tempos que não param de correr. (CHAVES, 2005, p.112)

Neste processo, entendemos como o feminino é um horizonte matricial. Pensando nisso, não podemos esquecer que o sexo é político, pois ele contém relações de poder instauradas no e através do corpo: 
Desfaço as maiores

Com as pontas dos dedos

Enquanto abro outras

Na concha do ventre

Encho as mãos de sangue

$\mathrm{Na}$ rosa aberta do seu peito

(TAVARES, 2011, p.224)

O sexo desfaz a pseudo- neutralidade da esfera individual do feminino, trazendo à baila laços existentes entre as relações interpessoais e a organização das políticas públicas. Não podemos deixar de comentar que a própria Angola, com o seu discurso cantalutista, da angolanidade e da liberdade, obliterou, muitas vezes, sob "políticas do silenciamento" (BUTLER, 2003, p. 41), discursos marginais, como, no caso, o das mulheres, que coloca em questão formas mais microscópicas de opressão. Neste sentido, Paula Tavares denuncia procedimentos de controle exercidos e defendidos por uma Angola que se pautava pela ideia de cultura para defender suas tradições, entre as quais se encontrava também o poder simbólico exercido pela "dominação masculina" (BOURDIEU, 2012, p. 7), que não pertencia à figura do colonizador, mas a um "poder-conhecimento" (FOUCAULT, 1998, p. 1) exercido por muitos chefes tradicionais. Como a própria poeta diz:

Me entrego a recolher

A memória do grito

Os sorrisos alargados de antigas fêmeas

Soltas das amarras e dos gritos

(TAVARES, 2011, p. 242)

Como veias finas na terra promove uma releitura da própria poética de Paula. Assim,

tradição e modernidade tecem alianças e se colocam como instrumentos ou ferramentas para melhor serem compreendidas as estórias/histórias de Angola e sua inserção ou não no mundo contemporâneo. Para isso, revisita muitos dos seus livros anteriores, fazendo uma intertextualidade inteligente com poemas seus e, outras vezes, com textos alheios. (SECCO, 2011, p. 277) 


\title{
A paisagem
}

Para Collot, o horizonte também é a fronteira que permite apropriar-se da paisagem, que se define como território do observador, isto é, "como espaço ao alcance do olhar e à disposição do corpo". (COLLOT, 2010, p. 206). Conforme foi apresentado, por meio da leitura dos poemas, partindo do horizonte literário da poesia de Paula Tavares - aquilo que define o sujeito-lírico no mundo e que a análise mostrou ser o feminino -, percebemos uma poesia, cujo elemento terra, recorrente ao longo da obra - mesmo em deslocamentos metonímicos, como: "lama", "chão", "barro", "caminho"; ou em verbos como "seguir", "pisar”, "dançar”, etc. -, se transforma numa paisagem especial, que dá conta, numa espécie de continuum, desse sujeito enunciador e do seu estar no mundo, respectivamente em: "Eu terra, eu árvore eu sinto/ todas as veias da terra em mim" (...) (TAVARES, 2011, p. 234) e "o chão é o limite/ Pendo para lá todos os dias" (Idem, p. 252).

$\mathrm{Na}$ tentativa de buscar uma imagem que dê conta da relação entre o horizonte feminino, a paisagem da terra e o sujeito-lírico enunciador, este traz à cena poética a figura da oleira, marca ancestral da cultura africana, pois "o oficio do barro é, nessas culturas, antigo, sendo ocupação de mãos femininas" (SECCO, 2011, p. 269). As oleiras são aquelas que "conhecem todas as cores da terra. Possuem os seus sítios especiais de colheita, que percorrem, esboroando entre os dedos pedaços de barro e passando a língua pelo fino pó que se entranha na pele." (TAVARES, 1998, p. 62). Por terem esse conhecimento, tocam "as veias finas" da terra - a paisagem literária - e fabricam o "coração de barro" -, ou seja, o poema: "só os poetas descobriram como é que as oleiras enterraram o coração de barro e, desde aí, lhe perseguem o sentido" (TAVARES, 1998, p. 63).

\author{
Não sei do céu \\ E das mil e uma noites \\ Só bordei o tapete \\ E treinei os dedos para as veias finas da terra \\ Isso de olhar a lua e crescer para o céu \\ É para iniciados \\ Mestres de cerimônias \\ Homens sábios
}

(TAVARES, 2011, p. 252)

Ofício feminino - e não "masculino" -, de "iniciados", a poeta, assim como as oleiras, aprende a mexer na paisagem da terra, através de um laborioso treinamento dos dedos, na mesma proporção da escrita, deixando os sinais da sua passagem. Trabalhar com as "veias finas 
da terra" é, assim, uma metáfora da própria escrita poética. É conhecer e ter consciência da finitude da vida e lidar com o "cheiro ácido do pântano/ O silêncio gelado dos nossos mortos/ A presença inquieta dos outros/ O lento movimento das dunas" (TAVARES, 2011, p. 247). Logo, pensar a terra, é reescrever poeticamente Angola, é re-pensar a história angolana, indo “(...) pelos passos das crianças gritar num sul mais/novo" (Idem, p. 218).

Conclui-se, através da escolha destas paisagens literárias - metáforas da escrita e das paisagens de Angola -, que a poeta, ao buscar os ecos "da terra", "o barro das origens", isto é, da tradição e da oralidade, promove uma re-leitura do passado histórico, repensando, de forma tensa, o presente, que se coaduna com a própria vida do sujeito-lírico feminino, o qual se encontra identificado à própria terra angolana:

Começa a história

Desde o princípio assim

Era uma vez um sol e a lua que lhe pertence

Mais a terra entre os dois e

A paisagem

Com os seus vultos parados

À espera da carne fresca

Planta a história de vozes

Sujeitos caminhos e esperança

Depois a história curva-se sobre a si própria

Medita duas vezes na água do rio

O fim está escrito

Nas linhas firmes das mãos.

(TAVARES, 2011, p. 232)

\section{Re-pensando o lirismo da buganvília}

Publicadas, ainda sob os espectros da guerra civil, as crônicas do livro O sangue da buganvília tem suscitado diversas leituras. Conforme Pâmela Maria do Rosário Mota (2014), a buganvília é, como metáfora do sangue derrubado pela guerra, símbolo combativo de renascimento perante as catástrofes e, por isso, um elemento gerador de utopia.

A crônica que dá nome ao livro inicia-se com uma reflexão sobre o ser vegetal da buganvília, marcando a sua condição de resistência e insubordinação perante as intempéries, mesmo possuindo uma aparência frágil. Por conta disso, a buganvília é capaz de desafiar, mesmo que 
cortada e morta, através do renascimento, porque possui a "teimosia das espécies que resistem" (TAVARES, 1998, p. 34). A crônica termina assim: "De uma coisa estou certa, venha quem vier, mudem as estações, parem as chuvas, esterilizem o solo, nós somos cada vez mais como as buganvílias: a florir em sangue no meio da tempestade" (Idem, p. 35).

É claro que toda crônica é datada, pois refere-se a um tempo datado. Entretanto, em se tratando de Paula Tavares, os seus textos cronísticos, em sua maioria, possuem também uma outra dimensão: eles germinam poeticamente através das veias finas da sua escrita. Ou seja, eles ganham uma dimensão poética.

No livro Como as veias finas da terra, há o seguinte poema que retoma a metáfora da buganvília:

\author{
Aqui as crianças estão escondidas e espreitam \\ o dia \\ com seus pezinhos de lã. \\ Amanhã preparo o corpo \\ De perfume e água fria \\ e vou ao sul no rasto delas. \\ Talvez entretanto no pátio dos olhos tenha \\ Nascido a buganvília
}

(TAVARES, 2011, p. 218)

Tânia Macedo (2011), ao fazer uma análise dos 25 anos da poesia de Paula, destacou símbolos que insistentemente se repetem: frutos, árvore, buganvília, etc.. Tratando-se de uma obra de intertextualidade e reflexão sobre a produção anterior, Como as veias finas na terra traz um alargamento de horizontes poéticos e retoma a imagem da buganvília, cuja origem e explicação se encontram na crônica apresentada anteriormente.

Entretanto, parece que, mesmo nos livros de Paula Tavares em que uma poiesis de desencanto se encena, diferentemente de Ritos de passagem, sua poética, como a buganvília, está voltando a renascer e a ganhar presença nos "pátios dos olhos" com temas de esperança, com crianças que estão escondidas e esperam o dia - parafraseando novamente a autora.

Podemos afirmar que a buganvília é marca do lirismo da poeta, que, mesmo escamoteado por um tom elegíaco, deve ser entendido como metáfora poética do próprio sul que resistiu à colonização e à guerra civil. Simboliza a tradição na sua tensa relação com o presente - "sempre a renascer". Também representa a escrita de Paula, a resistência da mulher, a esperança, a própria Angola. Poeta é quem escreve, mesmo em tempos sombrios. E, mesmo que diga pala- 
vras "amargas como os frutos", segundo Paula, "a poesia é coisa viva e líquida e respira todos os pequenos espaços que encontra, mesmo no mundo doente em que vivemos." (TAVARES Apud SECCO, 2014, p. 104)

\begin{abstract}
A poesia de Paula nos entra pelas veias, nos apanha por inteiro, levando-nos a reflexões, em meio a sensações intensas. Cada verso seu estica, ao máximo as palavras, tirando, de cada uma, múltiplos sentidos. É arco e lira, é seda e lã. É areia e água, terra e cheiros, frutos e desertos. (SECCO, 2011, p. 279)
\end{abstract}

\title{
REFERÊNCIAS
}

BHABHA, Homi K. O local da cultura. Tradução de Myriam Ávila. Belo Horizonte: Editora da Universidade Federal de Minas Gerais, 2005.

BOURDIEU, Pierre. A dominação masculina. Tradução de Maria Helena Kühner. Rio de Janeiro: Bertrand Brasil, 2012.

BUTLER, Judith. Problemas de gênero. Tradução de Renato Aguiar. Rio de Janeiro: Civilização Brasileira, 2003.

CHAVES, Rita. Angola e Moçambique - experiência colonial e territórios literários. Cotia: Ateliê Editorial, 2005.

COELHO, Eduardo Prado. A mecânica dos fluidos. Lisboa: Imprensa Nacional, s/d.

COLLOT, Michel. "Do horizonte da paisagem ao horizonte dos poetas". Tradução de Eva Nunes Chatel. In: ALVES, Ida Ferreira; FEITOSA, Márcia Manir M. Literatura e Paisagem: perspectivas e diálogos. Niterói: Editora da Universidade Federal Fluminense, 2010.

. O sujeito lírico fora de si. In: encurtador.com.br/gkQU8 Acesso em 9 de novembro de 2015.

Poética e filosofia da paisagem. Tradução de Ida Alves... [et al]. Rio de Janeiro: Editora Raquel, 2013.

DELEUZE, Gilles; GUATTARI, Félix. Kafka, para uma literatura menor. Tradução de Rafael Godinho. Lisboa: Assírio e Alvim, 2003. 
FOUCAULT, Michel. Microfísica do poder. Tradução de Roberto Machado. Rio de Janeiro: Edições Graal, 1998.

FRIEDRICH, Hugo. Estrutura da lírica moderna. Tradução de Marise M. Curioni. São Paulo: Livraria Duas Cidades, 1978.

HALL, Stuart. A identidade cultural na pós-modernidade. Tradução de Tomaz Tadeu da Silva e Guacira Lopes Louro. Rio de Janeiro: DP\&A, 2006.

LIMA, Luiz Costa. Limites da voz Montaigne, Schlegel. Rio de Janeiro: Rocco, 1993.

LUKÁCS, Georg. Sobre a essência e a forma do ensaio: uma carta a Leo Popper. Tradução de Mario Luiz Frungillo. In: Revista UFG. Volume 9. Número 4. Goiânia, 2008.

MÂCEDO, Tânia Celestino de. A delicadeza: a força da poesia. In: Mulemba. Revista do Setor de Literaturas Africanas - UFRJ. Ano 3. Número 4. Rio de Janeiro, 2011.

MOTA, Pâmela Maria do Rosário. Entre "as veias finas" da escrita: metáforas do sangue na poética de Paula Tavares. Rio de Janeiro: Dissertação de Mestrado defendida na UFRJ, PPGLV/UFRJ, 2014.

SANTOS, Boaventura de Sousa. Epistemologias do sul. Coimbra: Almedina, 2009.

SECCO, Carmen Lúcia Tindó. Afeto \& poesia. Ensaios e entrevistas: Angola e Moçambique. Rio de Janeiro: Editora Raquel, 2014.

. As veias pulsantes da terra e da poesia. In: TAVARES, Ana Paula. Amargo como os frutos. Rio de Janeiro: Pallas, 2011.

TAVARES, Paula. Amargos como os frutos. Rio de Janeiro: Pallas, 2011.

. A cabeça de Salomé. Lisboa: Caminho, 2004.

. O sangue da buganvília. Mindelo: Centro Cultural Português Praia - Mindelo, 1998.

. Oralidade é meu culto. Entrevista de Paula Tavares a Pedro Cardoso. In: AUSTRAL $\mathrm{n}^{\mathrm{o}}$ 78. Luanda, 7/11/2010. Texto gentilmente cedido pela TAAG - Linhas Aéreas de Angola. Disponível em: http://www.buala.org/pt/cara-a-cara/a-oralidade-e-meu-culto-entrevista-a-anapaula-tavares. Acesso em 10 de novembro de 2015. 